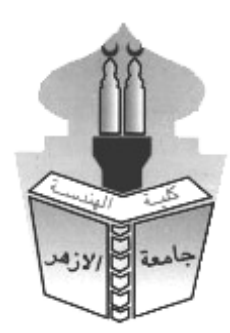

\title{
EFFECT OF CORRUGATION PANEL WIDTH OF COMPOSITE PLATE GIRDERS WITH CORRUGATED TRIANGULAR WEB
}

\author{
Hosny H. F. ${ }^{1}$, Shaat A. A ${ }^{2}$, El-serwi A. A. ${ }^{2}$, and Sayed-Ahmed E.Y ${ }^{3}$ \\ ${ }^{1}$ Bsc in Structural Engineering, Ain Shams University, Cairo, Egypt \\ 2Structural Engineering department, Ain Shams University, Cairo, Egypt \\ ${ }^{3}$ Construction Engineering department, American University in Cairo, Egypt
}

\begin{abstract}
this paper is concerned with composite plate girders with triangular corrugated webs. Finite element analysis using the computer package ABAQUS is employed to investigate the behavior and ultimate strength capacity of the girder. Parameters that affect the behavior of these girders are slenderness of the web $d / t$, web panel aspect ratio $b / d$, width to the depth of corrugation ratio $\mathrm{b}_{\mathrm{h}} / \mathrm{h}$. Influence of these parameters on the collapse behavior is examined. Results are obtained in terms of ultimate strength, failure mechanism and load-deflection curves from the finite element analyses and, some typical results are presented herein.
\end{abstract}

\section{INTRODUCTION}

Providing a profile pattern shape to the plate gives element sufficient increase in the strength this effect is called corrugation or accordion effect. Growing in strength is resulted from the inertia increase. Corrugated plates may be presented in various shapes trapezoidal (trapezium geometry), curved (sin wave), zigzag or triangular, rectangular etc. Merging composite action benefits with corrugation effect worthiness resulted in a valuable section. Composite steel concrete beams with corrugated steel web deemed as a modern technique in structural engineering. The corrugated web can be simulated as panels supported each other in vertical direction and restrained by flange at horizontal direction. Stability of corrugated web may be lose due to three modes of buckling: Local buckling mode, Global buckling mode \& Interactive buckling (Gajdzicki \& Perlinski, 2016; Yamazaki, 2001). Figure 1 shows these three modes. Local buckling of a one panel occurs in the case of higher aspect ratio. When the depth of panel is relatively large than its width, the single panel tends to buckle alone and do not share buckling with adjacent panels. (Galambos, 1998; Timoshenko \& Gere, 1961) stated an approximate equation using stationary potential energy theorem to estimate the elastic buckling strength in this mode. At dense corrugation geometry another buckling mode occurs which is global buckling mode at which the buckling wave pass through many panels not single one. And this mode also expressed as diagonal buckling. Occurs mainly in relatively low corrugation angle and depth (Sayed-Ahmed, 2003). Shear strength in case of global buckling limit stated by (Easley \& McFarland, 1975; Peterson \& Card, 1960) If we consider the corrugated web as an orthotropic plate with a corrugation depth (a thickness) of $d \tan \alpha$ then the shear stress can be estimated. They also defined shear strength of the global buckling mode using the Ritz method. The buckled shapes emerged from interactive buckling mode are not as clear as those of global or local buckling mode but they vary according to the geometry of the corrugated web (Yi et al., 2008). 


\section{NUMERICAL MODEL (FINITE ELEMENT ANALYSIS)}

(Abaqus, 2013) is the program was used in the analysis presented in this paper. Threedimensional models were developed. The Concrete slab was modelled using solid element (C3D8R) which was found the best element to capture all behavior of the slab in thickness and span directions. Reinforcement bars embedded in
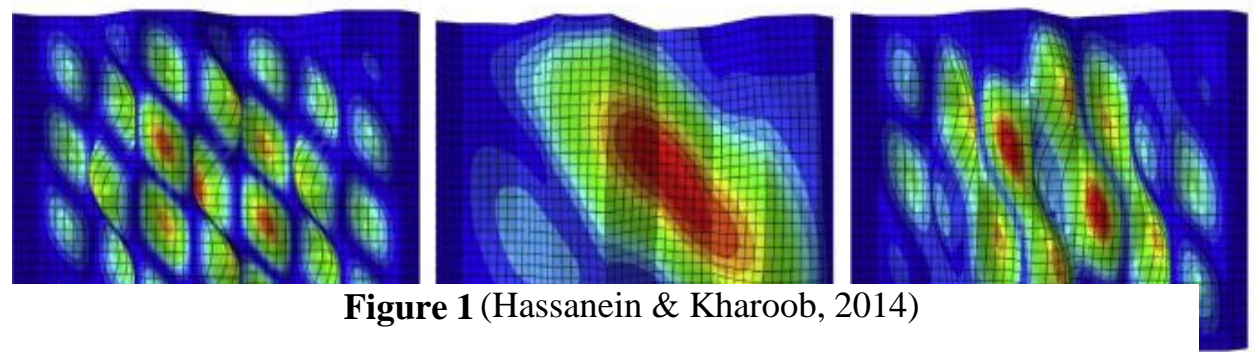

Local buckling

Global buckling

Interactive buckling

Figure 2 (Hassanein \& Kharoob, 2014)

concrete were modelled by deformable planar wire and were assigned to (T3D2) A- two-node linear 3-d truss element. it was found that for the corrugated web beam its better to be simulated using shell element (S4R) a thin doubly curved shell with the considering of reduced integration and hourglass control and formed from four nodes. Five degrees of freedom three degrees for translation in $\mathrm{X}, \mathrm{Y} \& \mathrm{Z}$ directions and two degrees for rotation $\mathrm{X} \& \mathrm{Y}$ are considered at each node. The same element with similar considerations used for bearing stiffener part. Concrete material was modeled using concrete damaged plasticity. elastic-plastic behavior of concrete under uniaxial compression test was modelled, in the assumption of that the stress strain follows a linear elastic relationship till stress reaches 0.3-0.4 Fc, then it starts to follow an ascending curve. To represent a hardening stage which expressed by (Carreira \& Chu, 1985) till reach the maximum compressive stress and then the post peak response is a descending part called strain softening stage (Figure 3) can be expressed as linear relationship.

$$
\sigma_{c}=\frac{f_{c}^{\prime} \gamma\left(\varepsilon_{c} / \varepsilon_{c}^{\prime}\right)}{\gamma-1+\left(\varepsilon_{c} / \varepsilon_{c}^{\prime}\right)^{\gamma}}
$$

where, $(\sigma c) \&(\varepsilon)$ is the compressive stress in concrete and the strain in concrete respectively. $\left(\mathrm{fc}^{\prime}\right) \&(\varepsilon \mathrm{c})$ is cylinder compressive strength of concrete and strain corresponding to ( $\left.\mathrm{fc}^{\prime}\right)$ in $\mathrm{MPa}$ respectively and $(\gamma)$ is defined as:

$$
\gamma=\left[\frac{f_{c}^{\prime}}{32.4}\right]^{3}+1.55
$$

Usually peak compressive strain for concrete $\varepsilon c^{\prime}$ is considered as 0.002 . In the present nonlinear FE analysis, the stress-strain behaviour of concrete in compression is assumed as linear elastic up to $0.4 \mathrm{fc}$ (Lasheen et al., 2016; Prakash et al., 2011). Steel material was modeled using a bilinear stress-strain relationship (Figure 4). A symmetry boundary condition was applied at one ends of the beam and the other end was rested on the hinged support. The plane of symmetry selected, was the plane at mid span of the beam, so only one half of the beam was modelled. $Z$-symmetry ( $Z$ axe is at the beam longitudinal direction) boundary condition was achieved by preventing the translation at Z-direction and rotation in X and $\mathrm{Y}$ the other two directions. Set of nodes of the bottom steel flange at the stiffeners location was assigned to a specified boundary condition, which prevent rotation and translation at both $\mathrm{Z}$ and $\mathrm{Y}$ direction respectively. The solution method implemented was the modified Riks technique. Local instabilities a lot occur in the nonlinear analysis of reinforced concrete 
components because of the large extents of cracking. The modified Riks method was used in the present study to avoid the local instabilities.

\section{Analysis of composite girders with triangular corrugated web}

A wide parametric study is conducted to examine the overall behavior of composite steel concrete beams with corrugated steel web. Figure 5 shows the overall view of the FEM model used in the study. The Goal of this parametric study is to explore different parameters and inspect their effect on the strength and the stiffness gain for the studied beam. The study focused in one type of corrugation which is triangular or zigzag profile

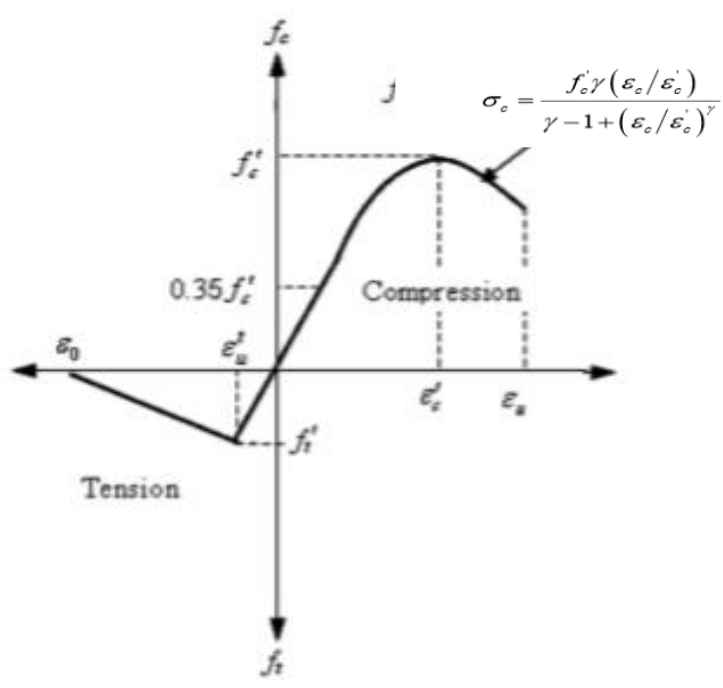

Figure 3 Stress-strain curve for concrete

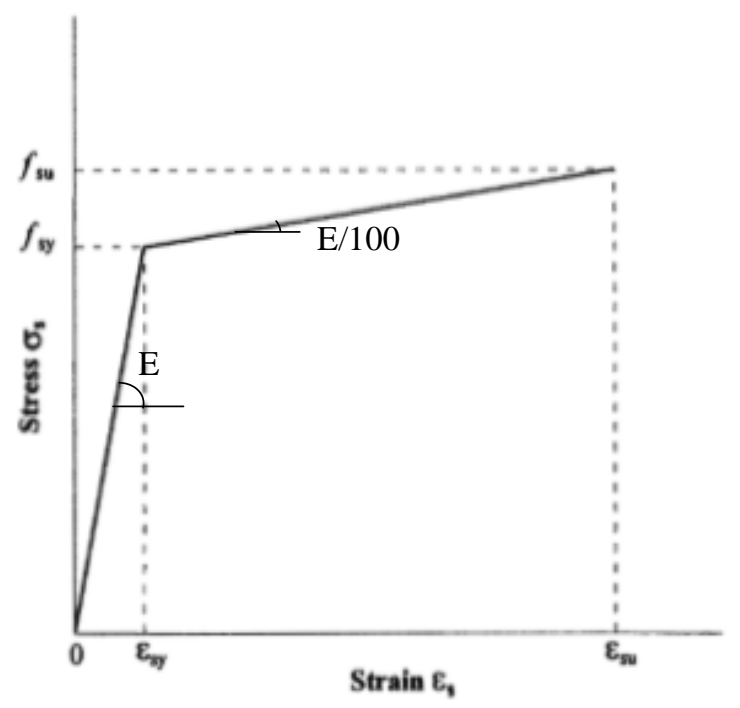

Figure 4 Stress-strain curve for steel

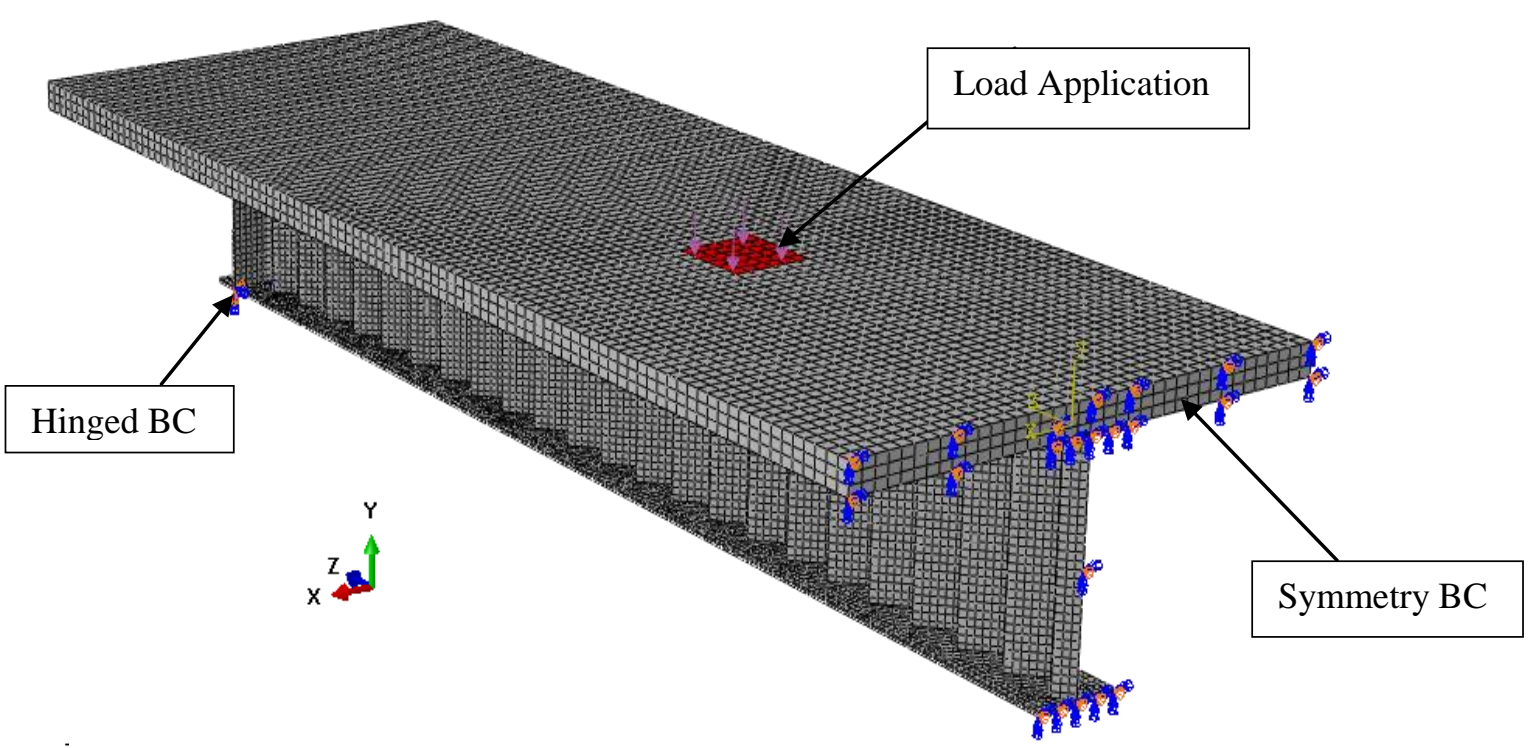

Figure 5 Finite element model overall view 
This study was proceeded using the finite element model previously described. The whole model geometry is kept constant, except for the corrugation profile and web slenderness ratio. The concrete slab depth and width are $1500 \mathrm{~mm}$ and $80 \mathrm{~mm}$ respectively. The steel beam has a top and bottom flanges of $250 \mathrm{~mm}$ breadth and a thickness of $12 \mathrm{~mm}$. Figure 6 shows the corrugation profile parameters. $12 \mathrm{~mm}$ thick stiffeners were inserted at $100 \mathrm{~mm}$ from both ends of beams span with length equal to the length of support ( $\mathrm{L}$ stiff. $=230 \mathrm{~mm}$ ). The clear span of the specimens was $7800 \mathrm{~mm}$. A reinforcement bars of T10 spaced with $100 \mathrm{~mm}$ at both directions placed in the concrete as a bottom mesh for concrete reinforcement purpose. At the elevation of $25 \mathrm{~mm}$ from concrete deck soffit. Degree of shear connection was kept constant in the current parametric study and it was a full composite action approach. Tie constrain between concrete bottom surface and the steel flange top face was introduced to the model, to achieve a case of no slip permitted between steel and concrete interface. Figure 7 shows the elevation of the tested beams and Figure 8 shows the cross section of beams.

shows the matrix of parameters used in the parametric study. Every beam took a unique ID

\begin{tabular}{cccc}
\hline \multirow{2}{*}{$\begin{array}{c}\text { Web Depth } \\
(\mathbf{d})(\mathbf{m m})\end{array}$} & $\begin{array}{c}\text { Web thickness } \\
(\mathbf{t})(\mathbf{m m})\end{array}$ & $\begin{array}{c}\text { Corrugation } \\
\text { angle }(\alpha)\end{array}$ & Panel width $(\mathbf{b})(\mathbf{m m})$ \\
\hline & & 10 & $120,150,250,350 \& 550$ \\
\cline { 2 - 3 } $\begin{array}{c}400,600, \\
800 \& 1,000\end{array}$ & $4 \& 8$ & 25 & $120,150,250,350 \& 550$ \\
\cline { 2 - 3 } & & 45 & $120,150,250,350$ \\
\cline { 2 - 3 } & & 60 & $120,150,250$ \\
\hline
\end{tabular}

depending on its parameters $(\mathrm{Zd} / \mathrm{t}-\alpha-\mathrm{b})$ for example (Z600/4-10-150) means a zigzag web beam of depth $600 \mathrm{~mm}$ and $10^{\circ}$ of corrugation angle with $150 \mathrm{~mm}$ corrugation panel width.

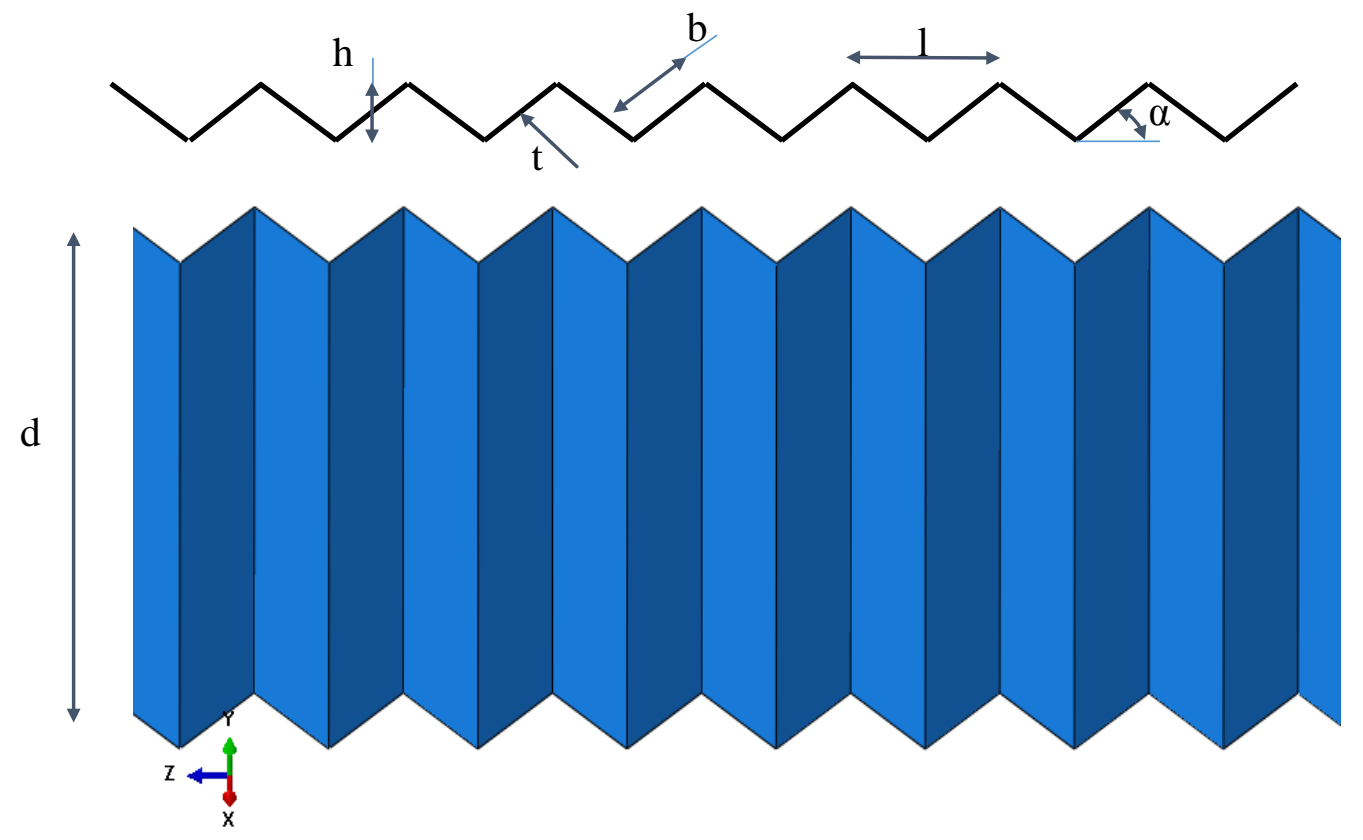

Figure 6 Corrugation profile geometry 
EFFECT OF CORRUGATION PANEL WIDTH OF COMPOSITE PLATE GIRDERS WITH CORRUGATED TRIANGULAR WEB

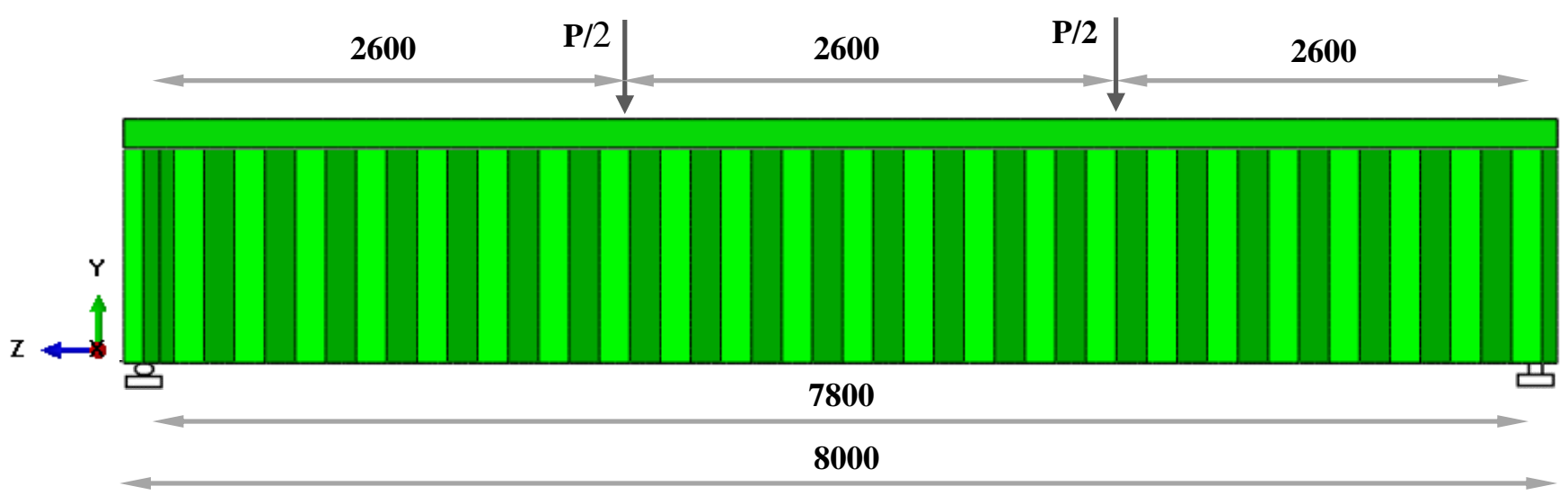

Figure 7 Elevation of tested beams

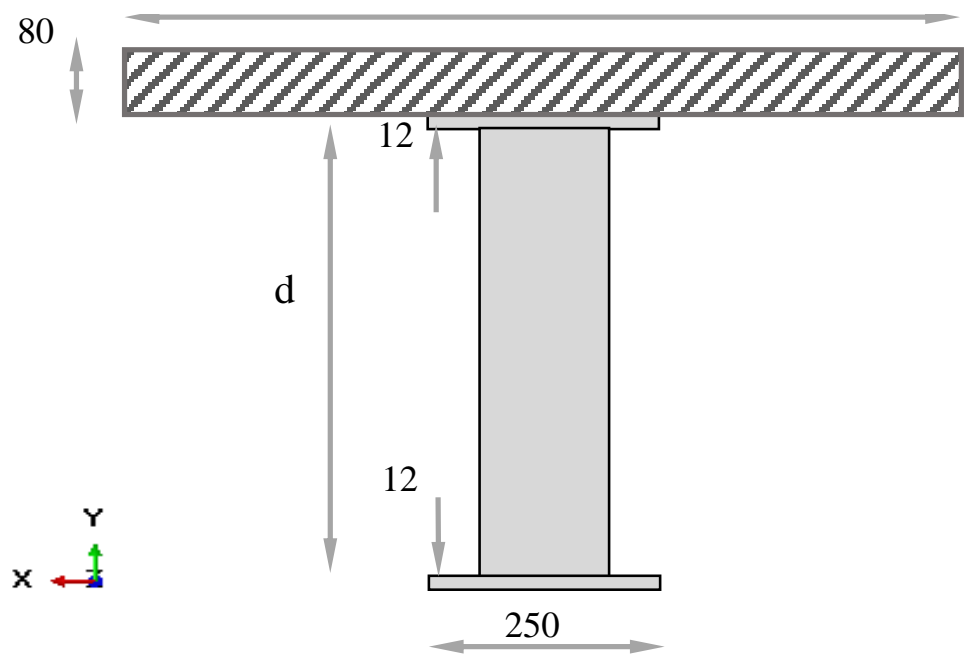

Figure 8 Cross section of tested beams

\section{Effect of Corrugation ranel wiatn}

Effect of panel width of a zigzag corrugated steel web beam in a composite section was investigated. The following section describes the effect of varying the panel width in terms of three main characteristics, which are strength of beams, initial elastic stiffness, and ductility of beams. To investigate the effect of panel width on every characteristic mentioned above, other parameters should be grouped together in various values. The following examination of panel width was mainly studied in major two groups of $4 \& 8 \mathrm{~mm}$ thickness of panel and for every group a depths of 400, 600, $800 \& 1000 \mathrm{~mm}$. Figure $18 \& 9$ Show a sample of load-deflection results for beams of web depth $600 \mathrm{~mm}$ and thickness of $4 \& 8 \mathrm{~mm}$ for at corrugation angle of $10^{\circ}$ and panel width of $120,150,250,350 \& 550 \mathrm{~mm}$.

\subsection{Strength of beams}

After studying the change of values of ultimate load with the change of panel width it was found that the effect should be studied for two ranges of corrugation angle. Range (1) for relatively small angles from $\alpha=10^{\circ}$ to $25^{\circ} \&$ Range (2) for large angles from $\alpha=45^{\circ}$ to $60^{\circ}$. Case of $8 \mathrm{~mm}$ thickness of panel, For range (1): it's found that at the corrugation angle of $10^{\circ}$ at the depth of $400 \mathrm{~mm}$ there isn't a significant effect on ultimate load. by varying the panel width from 120 to $550 \mathrm{~mm}$, however there was a slightly decrease in ultimate load with increase of panel width till the panel width of $350 \mathrm{~mm}$ and after this the ultimate load didn't record any notable change. However at the depth of $600 \mathrm{~mm}$ the increase of pane width was accompanied by decrease in ultimate load with a remarkable rate till the width of $250 \mathrm{~mm}$ and the decreasing rate became steeper. When the depth of web reaches $800 \mathrm{~mm}$ and $1000 \mathrm{~mm}$ same notes had been found. 
Previous notes was applicable for angle of $25^{\circ}$, but in addition to that it was noticed that at the panel width bigger than $350 \mathrm{~mm}$ both angles behaves closer to others in the response towards the ultimate load capacity change. For range (2): it's found that at the higher corrugation angle that the panel width has a minor effect on the ultimate load carried by the beam. Case of $4 \mathbf{~ m m}$ thickness of panel, For range (1): varying the panel width at the depth of $400 \mathrm{~mm}$ has not a significant effect on ultimate load. However the note is that the both angles behave closer to other towards the ultimate load at the panel width of $350 \mathrm{~mm}$ to $550 \mathrm{~mm}$. for relatively larger depths from $600 \mathrm{~mm}$ to $1000 \mathrm{~mm}$ the it can be said that the ultimate load majorly affected by the panel width change. The effect can be organized in two ranges, one before 200 $\mathrm{mm}$ width at which the $10^{\circ}$ exhibits better strength from $25^{\circ}$ but the decreasing of strength continued in a sharp rate till both angles are similarly gains same strength. And at the second range of panel width after $200 \mathrm{~mm}$ the corrugation angle $25^{\circ}$ showed better strength than $10^{\circ}$. Concerning range (2): similarly it's found that at the higher corrugation angle that the panel width has a minor effect on the ultimate load carried by the beam. Figure 110 shows a sample of panel width effect on strength of beams with web depth of $600 \mathrm{~mm}$ and thickness of $4 \mathrm{~mm}$.

4.2. Elastic stiffness Case of $8 \mathrm{~mm}$ thickness of panel,

for range (1): it is found that the increase of panel width was accompanied by an increase in stiffness with a constant rate and both angles follows same rate. For range (2): it's found that at the higher corrugation angle that the panel width has not a notable effect on the stiffness of beams.

Case of $4 \mathbf{~ m m}$ thickness of panel, for range (1): similarly, it is found that the increase of panel width was accompanied by an increase in stiffness with a constant rate and both angles follows same rate. Until panel width of $350 \mathrm{~mm}$, and after this the rate of stiffness gaining with panel width increase at $25^{\circ}$ became lower than at $10^{\circ}$. For range (2): it has found that at the higher corrugation angle that the panel width has not a notable effect on the stiffness of beams. Figure 111 shows a sample of panel width effect on stiffness of beams with web depth of $600 \mathrm{~mm}$ and thickness of $4 \mathrm{~mm}$.

\subsection{Ductility of beams}

Case of $8 \mathrm{~mm}$ thickness of panel, for range (1): At lower depth of $400 \mathrm{~mm}$, it is found that the increase of panel width was accompanied by a decrease in ductility with a considerable rate, until panel width of $350 \mathrm{~mm}$ then the rate became lower than before. However, at higher depths from 600 to $1000 \mathrm{~mm}$ the relation converted to be an increasing of ductility with increase of panel width until a width of $250 \mathrm{~mm}$, increase of panel width after this value causes a ductility decrease. For range (2): it was found that at the higher corrugation angle, the panel width increase was accompanied by increase in ductility till the panel width of 150 then the relation follows a decreasing rate till $550 \mathrm{~mm}$. Case of $4 \mathbf{~ m m}$ thickness of panel, for range (1): it was found that the panel width increase was accompanied by increase in ductility till the panel width of 250 then the relation follows a decreasing rate till $550 \mathrm{~mm}$, similarly that was applicable for range (2).

Table 1 The matrix of parametric study models

\begin{tabular}{cccc}
\hline \multirow{2}{*}{$\begin{array}{c}\text { Web Depth } \\
(\mathbf{d})(\mathbf{m m})\end{array}$} & $\begin{array}{c}\text { Web thickness } \\
(\mathbf{t})(\mathbf{m m})\end{array}$ & $\begin{array}{c}\text { Corrugation } \\
\text { angle }(\boldsymbol{\alpha})\end{array}$ & Panel width (b)(mm) \\
\hline & & 10 & $120,150,250,350 \& 550$ \\
\cline { 2 - 3 } $\begin{array}{c}400,600, \\
800 \& 1,000\end{array}$ & $4 \& 8$ & 25 & $120,150,250,350 \& 550$ \\
\cline { 2 - 3 } & & 45 & $120,150,250,350$ \\
\hline
\end{tabular}


EFFECT OF CORRUGATION PANEL WIDTH OF COMPOSITE PLATE GIRDERS WITH CORRUGATED TRIANGULAR WEB

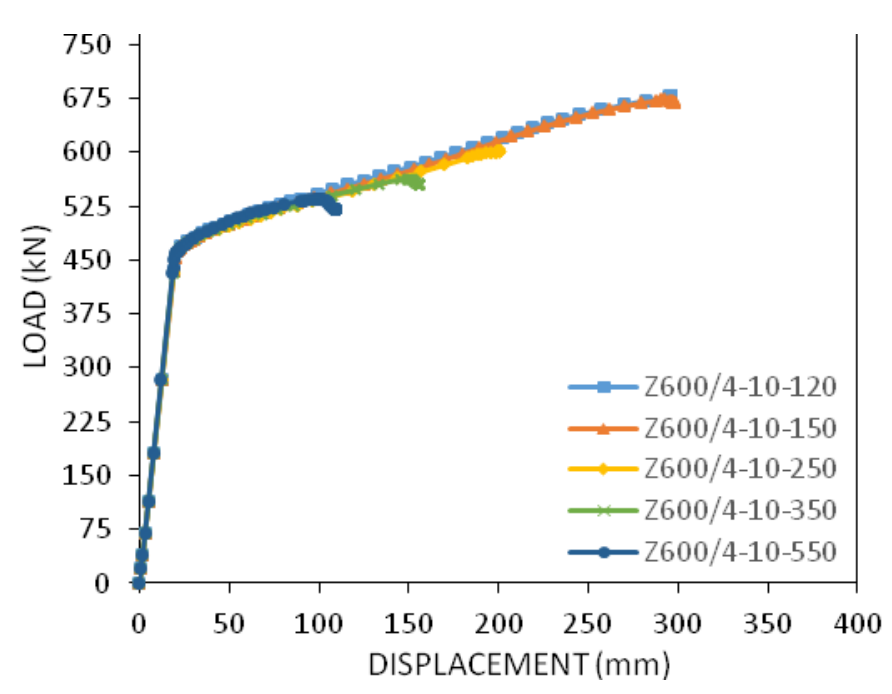

Figure 8 Load-deflection for $d=600 \& t=4$

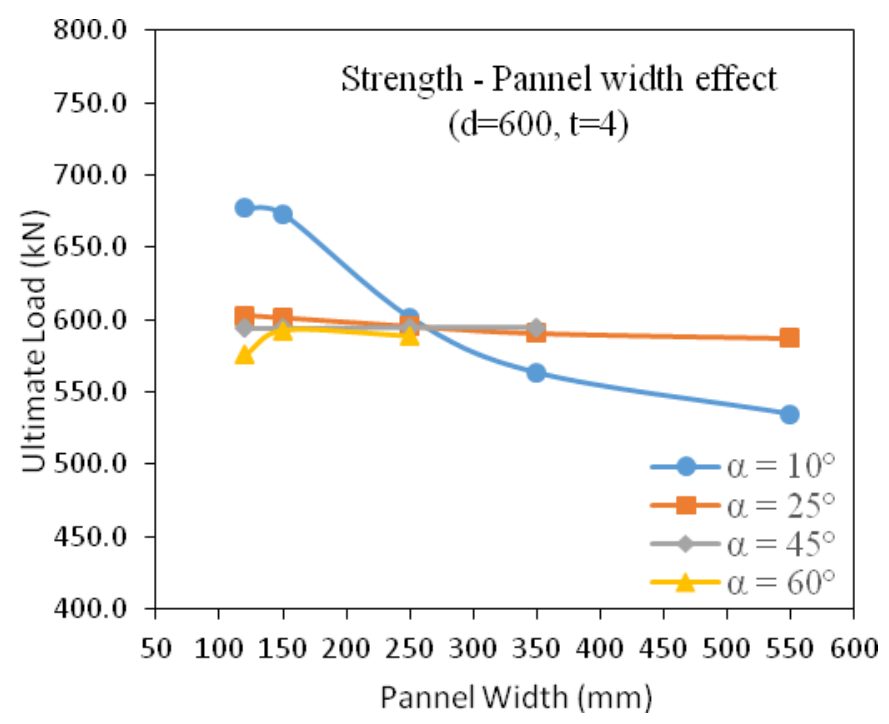

Figure 10 Panel width effect on strength

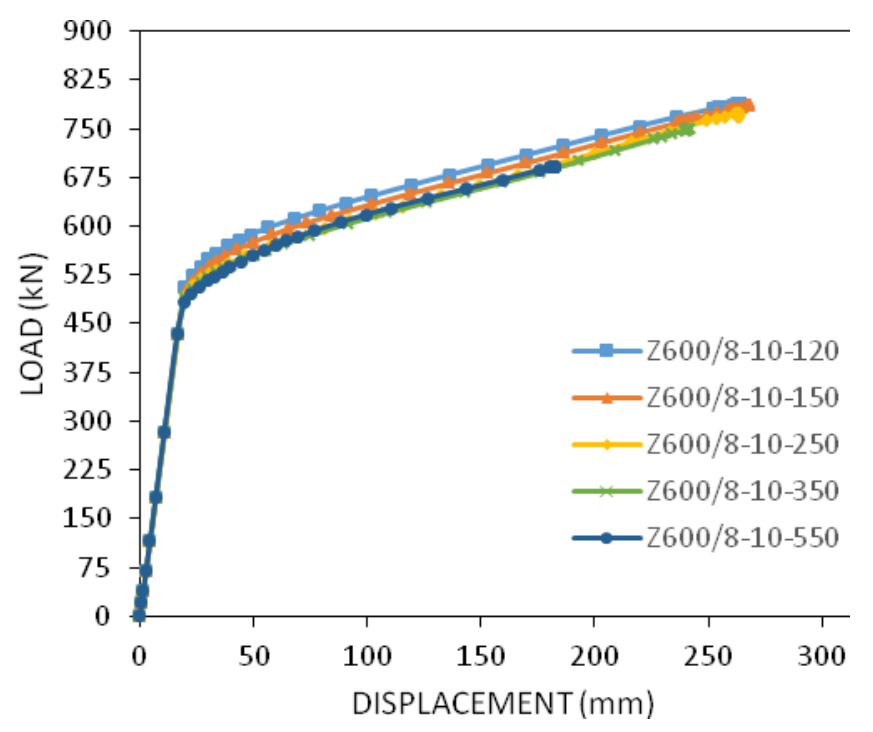

Figure 9 Load-deflection for $\mathrm{d}=600 \& \mathrm{t}=8$

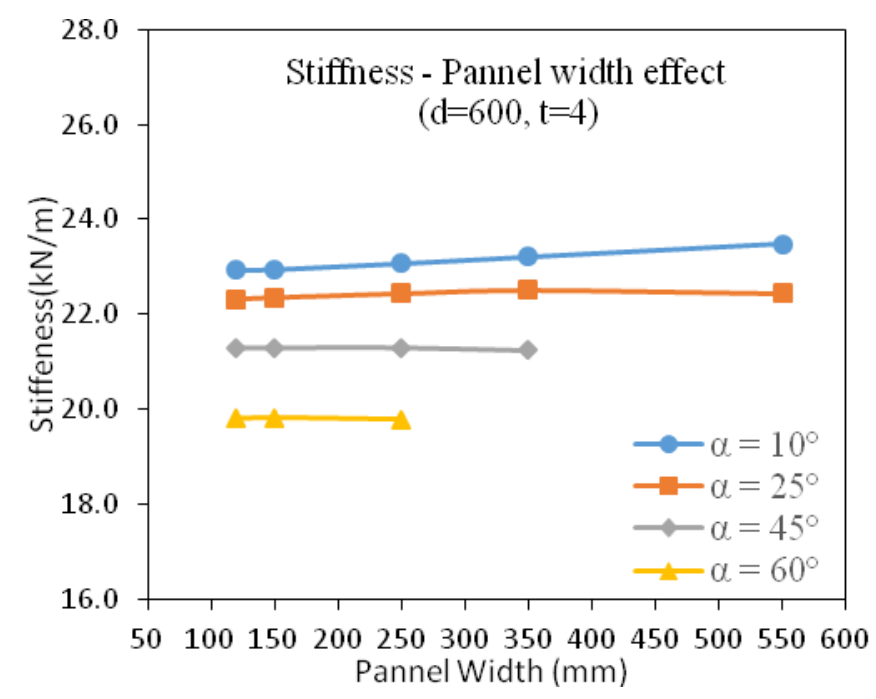

Figure 11 Panel width effect on stiffness 
EFFECT OF CORRUGATION PANEL WIDTH OF COMPOSITE PLATE GIRDERS WITH CORRUGATED TRIANGULAR WEB

\section{CONCLUSION}

Ultimate load behavior of Composite Plate Girders With Corrugated Triangular Web has been examined in this study. Finite element model was developed using a finite element package, known commercially as ABAQUS to carry out nonlinear finite element analysis on the girders. A comprehensive parametric investigation was conducted numerically using the adopted finite element model. Four main parameters were studied: the panel width of the corrugation (b), angle of the corrugation $(\alpha)$, web depth and thickness (h\&t) respectively. Results are presented in terms of load-deflection plots, deformed shapes of girders after failure and ultimate loads. this paper concentrated on the effect of panel width. panel width affected the strength of beams majorly in the lower thickness of $4 \mathrm{~mm}$. from the study it was found that at specific value of approximately $200 \mathrm{~mm}$, at which the strength is equal at all angles of corrugation ranged from $10^{\circ}$ to $60^{\circ}$. panel aspect ratio has a major effect on the strength of beams, and to achieve maximum strength in case of using corrugation angles larger than $25^{\circ}$ it was found a specific aspect ratio not to ignore. This specific value varied from depth to another. At depths of $600,800 \& 1000 \mathrm{~mm}$ the specific value of aspect ratio was $2.4,3.5 \& 5$ respectively. shear resistance, Elastic stiffness and ductility are influenced significantly by the width and depth of the corrugation. Larger corrugation width and depth, in view of bigger plate slenderness, has been observed to result in a drop in ultimate shear strength. It is, therefore, necessary to arrive at optimum values for the corrugation width and depth in order to achieve an efficient design.

\section{REFERENCES}

1. Abaqus. (2013). 6.13, Analysis User's Manual. Dassault Systemes Simulia Corp., Providence, $R I$.

2. Carreira, D. J., \& Chu, K.-H. (1985). Stress-strain relationship for plain concrete in compression. Paper presented at the Journal Proceedings.

3. Easley, J. T., \& McFarland, D. E. (1975). Buckling formula for corrugated metal shear diaphragms.. ASCE Journal of Structural Engineering, , 101(7): 1403-1417.

4. Gajdzicki, M., \& Perlinski, W. (2016). Shear strength of trapezoidal and sinusoidal corrugated steel webs. Paper presented at the Recent Progress in Steel and Composite Structures: Proceedings of the XIII International Conference on Metal Structures (ICMS2016, Zielona Góra, Poland, 15-17 June 2016).

5. Galambos, T. V. (1998). Guide to stability design criteria for metal structures: John Wiley \& Sons.

6. Hassanein, M., \& Kharoob, O. (2014). Shear buckling behavior of tapered bridge girders with steel corrugated webs. Engineering Structures, 74, 157-169.

7. Lasheen, M., Shaat, A., \& Khalil, A. (2016). Effective width for steel-light weight concrete composite girders. Phd Thesis. Cairo : Civil engineering Ain Shams University.

8. Peterson, J. M., \& Card, M. E. (1960). Investigation of buckling strength of corrugated webs in shear. . NASA, Washington, D.C.,Technical notes D24.

9. Prakash, A., Anandavalli, N., Madheswaran, C., Rajasankar, J., \& Lakshmanan, N. (2011). Three dimensional FE model of stud connected steel-concrete composite girders subjected to monotonic loading. International Journal of Mechanics and Applications, $1(1), 1-11$.

10. Sayed-Ahmed, E. Y. (2003). Girders with Corrugated Steel Webs: Buckling Modes and Numerical Modeling. Proceedings, Advances in Structures: Steel, Concrete, Composite and Aluminum, Sydney, Australia, 807-812.

11. Timoshenko, S. P., \& Gere, J. M. (1961). Theory of elastic stability. 1961. McGrawHillKogakusha Ltd, Tokyo, 109.

12. Yamazaki, M. (2001). Buckling strength of corrugated webs. Structural Engineering Research Paper, JSCE A, 47, 19-26.

13. Yi, J., Gil, H., Youm, K., \& Lee, H. (2008). Interactive shear buckling behavior of trapezoidally corrugated steel webs. Engineering Structures, 30(6), 1659-1666. 